\title{
Interview
}

\section{In conversation with Heinz Wolff: Part I}

Sidney Bloch interviewed Dr Heinz Wolff at the Royal College of Psychiatrists on 9 November 1988.

SB It is almost half a century since you graduated from Cambridge in medicine and yet at one point you might have been a mathematician.

HW Yes, when I left school in Hamburg, in North Germany, and went to Cambridge in 1934 I was

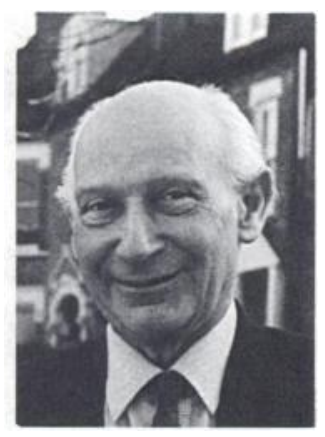
still undecided whether to study medicine or mathematics. I therefore started by doing both and took Part I of the Tripos in the Natural Sciences as well as in mathematics. I then took Part II in physiology and went to UCH to qualify in medicine but mathematics has remained one of my interests.

SB What determined that it was going to be medicine rather than mathematics in the end?

HW I think my great interest and enjoyment of pure mathematics which started when I was twelve may in part have been reinforced by my having been a rather withdrawn adolescent. I felt more at ease when dealing with abstract concepts and symbols like infinite numbers than with people. I changed a lot during my years at Cambridge and preferred contact with people after all. This made me decide to give up mathematics as a career and make medicine my profession, but I can still get fascinated by mathematical problems.

SB Before we leave Hamburg, how did you actually get from there to England as a student?

HW I was very fortunate because this was much easier for me and my immediate family than for most other families of Jewish origin in Germany at the time. My father, who was practising as a general practitioner in Hamburg, was born in Manchester and kept his British nationality while my mother, whose family lived in Hamburg, was German. We therefore had no difficulty in leaving Germany and coming to England. I was the first to leave in 1934 after finishing school and stayed with our relatives in Manchester before going to Peterhouse, Cambridge. This meant that I could spend a few months at a tutorial college in Manchester to prepare for my entrance examination to Cambridge. This was important because my schooling at a classical gymnasium in Hamburg had included hardly any teaching in science so that I had to make up for this. I was also determined to learn to think and write fluently in English; I still remember feeling very pleased when I started to dream in English. In fact, for me personally, coming to England, felt like coming home because even as a small boy I used to think of England as the 'land of the angels', a feeling fostered by my father who always preferred England to Germany in spite of my mother's German background and her family to whom we were very close.

SB Was there any impact on you of the Nazi era, even at this early stage in 1933-1934?

HW Yes, of course. We were very aware of the threat of Nazi persecution, and I felt this particularly at school. We were especially concerned about my grandparents, my mother's parents, and her sister. It was my father who helped them to join us in London in 1938, shortly before the war. Otherwise they would almost certainly have died in a concentration camp, although we did not fully realise this at the time. This move from one country to another actually helped me personally to adapt and relate to people with different backgrounds and nationalities. Perhaps this also accounts for my dislike of any form of rigidity and orthodoxy in politics or religion.

SB Certainly, the advent of the war had an influence on your life because you spent, was it five years in the Services, and most of that in India?

HW Yes, I look back on my time in the RAMC from 1941 to 1946 as a very varied and valuable experience. I qualified at $\mathrm{UCH}$ in 1940 and after my two house jobs, including one as house physician to Sir Thomas Lewis, I went 
into the army and was soon sent to India with the 17th British General Hospital. Suddenly I found myself in charge of two hundred or so acutely ill British and Indian soldiers in a tented general hospital in Dehra Dun, in the foothills of the Himalayas. I quickly learnt to take full responsibility for patients with all kinds of acute illnesses, including tropical diseases, not to mention having to give anaesthetics, which I found very frightening at first. At the same time I enjoyed getting to know Indian families and their religion and culture. I also spent two months' leave walking across the Himalayas from Darjeeling through Sikkim into Tibet, an experience I shall never forget.

My time in India also gave me my first experience of psychiatry. At that time there were virtually no psychiatrists in the army in India, and they were asking for volunteers. I therefore spent three months to be 'trained in psychiatry' at a European mental hospital in Ranchi, Bengal. In fact, this has remained my only formal training in psychiatry. I read a great deal and learnt to give ECT without anaesthetics or muscle relaxants, and came, for the first time, in contact with seriously ill psychiatric patients. As a student at UCH I had only done one week of psychiatry, mainly lectures and demonstrations at a local mental hospital, I believe at Shenley. After that I went back to the 17th BGH, by then in Dacca, Bangladesh, to continue to do medicine but I also became 'psychiatrist to Eastern India' for about a year and a half. This meant a lot of travelling and I saw many soldiers who had become psychiatrically ill during the fighting in Burma, including Gurkhas who had developed hysterical conversion symptoms; these were often cured by a Buddhist priest who acted as my interpreter and used exorcism and suggestion which seemed to be very effective. After the war, I returned to $\mathrm{UCH}$ as a medical registrar to continue my medical career at home.

SB I have the impression that it was something of a tussle between medicine and psychiatry and I also wonder how you actually resolved it?

HW Yes, that is true. I was very happy doing medicine and enjoyed practising it and later on teaching medical students at UCH. I also found that I was more interested in the patient as a person than in any particular specialised branch of medicine. As I enjoyed teaching I hoped one day to get on the staff of a teaching hospital, but realised this would be difficult unless I decided to specialise in some relatively narrow speciality, and that went against the grain where I was concerned. This also led to my growing interest in psychosomatic medicine, but there were no opportunities to specialise in that subject.

SB Yet, at that early stage in your career, it seems like medicine itself was winning the day. Your MRCP and the influence of eminent figures like Sir Thomas Lewis and Sir Francis Walshe?

HW Yes, they both had an important influence on me, Sir Thomas Lewis particularly. As a physician and as a teacher he insisted on extreme accuracy in history-taking and observation. I still remember that after telling him as his house physician that a patient's attacks of angina tended to come on during a row, he asked me who he had had a row with and about what, a question I couldn't answer. Ever since I have paid great attention to detail when taking a history in medicine, psychiatry and especially during psychodynamic assessment interviews and during psychotherapy; I therefore owe a great debt to Sir Thomas Lewis. I also know that my experience as registrar to Sir Francis Walshe, after the war, laid the basis for my continuing interest in neurology and the relation between the brain and the mind.

SB Psychosomatic medicine as a concept was much in its heyday around this time, in the ' 30 s and in the '40s. Were you involved in this?

HW Yes, I certainly was, though a little later. In the 1950 s I became one of the early members of the Society for Psychosomatic Research in Britain; later on, as president of the Society, I organised several of its conferences which are still being held annually at the Royal College of Physicians. I also attended many of the European Conferences on Psychosomatic Research in different countries in Europe and made many friends abroad. I did not, however, go along with the idea that there were a few specific psychosomatic disorders as proposed by Franz Alexander in Chicago, and by others working in that field. I have always preferred to think in terms of a psychosomatic approach to be applied to every patient whatever illness he happens to be suffering from.

SB As you say, the Society for Psychosomatic Research continues today and holds excellent conferences annually. What do you see as its main contribution in the contemporary psychiatric scene?

HW You are asking an interesting and controversial question. When I originally became interested in psychosomatic medicine, both in my clinical work and in teaching, my main interest was in the psychodynamic aspects. I considered it important to get in touch with the patient's subjective experience, how he 
felt about being ill and its consequences, and especially how the onset and course of his illness might be related to internal psychological conflicts and interpersonal stresses. In the early days, members of the Society for Psychomatic Research shared many of these interests. Nowadays, much of psychosomatic research is directed towards the observation of objective and measurable data. Such research is of course essential, as in medicine and psychiatry in general, but I fear that the original purpose of psychosomatic medicine, to pay attention to each individual patient's subjective experience and how this relates to his illness, often gets lost in the process. Also, the psychoanalytic aspects relevant to psychosomatic medicine are often ignored or overlooked; by this I don't mean out-of-date classical psychoanalysis but analysis as it is practised today, with its emphasis on early object relationships.

SB I suppose that might be a message you would want to convey to the new liaison psychiatry group in the College which is obviously looking now towards its functions and purposes.

HW Yes, I belong to the Liaison Group but, having retired from hospital work seven years ago, I have only been at a few of its meetings. I do hope that the Liaison Group of the College will ultimately be able to integrate both these approaches. Papers on epidemiological and psychophysiological research tend to predominate at present. These are obviously important but in actual clinical liaison work and in teaching the psychosomatic approach to students, doctors and psychiatrists it is even more important to understand the individual patient's inner world, his relationship to his psychosocial environment, and how these interact and affect his illness. I do hope the Liaison Group will in future pay more attention to these aspects than it does at present. Otherwise the essence of liaison work will get lost.

SB You mentioned a moment ago that your particular interest within psychosomatic medicine was to look at the internal world of the patient, a sort of psychodynamic approach. How in fact did your interest in psychoanalytic psychotherapy evolve?

HW This is quite a long story. In my last year at school I came across Freud's Interpretation of Dreams. I was fascinated by his attempt to understand the meaning of dreams by careful study of the individual's mental processes, including those which were unconscious. The role of symbolism in dreams impressed me particularly, perhaps partly because of my interest in mathematics where symbols and symbolic logic play such an important part. I remember writing an essay on dreams and forgetting in my last year at school, using the concept of repression. This interest did not find further expression until I came to Cambridge where a psychoanalyst, Karin Stephen, sister-in-law of Virginia Woolf, came to give lectures once a week on psychoanalytic concepts. This refreshed my interest in psychoanalysis and I began to read some of Freud's papers and case histories and the work of later analysts. When I started my clinical training at UCH I therefore decided to have a personal analysis. I think I should mention one important personal reason that made me have analysis myself. My mother had died suddenly when I was only eight years old and I had not yet properly recovered from this shock; my analysis helped me a great deal with that. I might add that the influence of losses on human development and on the origin of mental or physical illness has always seemed to me to be crucial. Freud, in his famous paper on 'Mourning and Melancholia', discussed the process of recovery from losses due to bereavement. Later Melanie Klein described what she called the depressive position, the way in which one has to learn to tolerate feelings of guilt and being sad and mourn, following a loss. I described some of these issues in a paper I wrote in 1977 on 'Loss, a Central Theme in Psychotherapy'.

SB I know the paper only too well, and indeed recommend it to all my trainees. ${ }^{*}$ It is in my view something of a classic. I can now see what motivated you to write the paper.

Talking about loss reminds me of the words of George Pollock, the Chicago psychoanalyst, when he says that all change involves loss. It seems that in the late 1950 s you were having to decide about your future - medicine or psychiatry, and either way you were going to lose something in the process. What actually happened?

HW Yes, that's very true. I had to make a choice which meant giving something up and losing something. It wasn't easy. I had by that time been for four years the Resident Assistant Physician at University College Hospital. This meant carrying a great deal of personal responsibility for in-patients, acute admissions, out-patients and the teaching of medicine. By that time my interest in the psychosomatic aspects and in psychotherapy had also grown considerably and I had to

*WoLfF, H. H. (1977) Loss: a central theme in psychotherapy. British Journal of Medical Psychology, 50, 11-19. 
make a choice. I think I survived the loss of giving up being a physician by joining the Department of Psychological Medicine at $\mathrm{UCH}$, at first as clinical assistant, under Roger Tredgold, and by concentrating on liaison work and psychotherapy. I had already treated a few patients with psychotherapy in his department and was extremely grateful to him for offering me these sessions at this critical time in my career. At the same time the liaison work kept me in touch with medicine and the medical wards where I had worked before.

Following that there was another important development. Dr Tredgold, Dr Dorothea Ball and I felt that students might learn more about psychological understanding, interviewing and the doctor-patient-relationship if they could take on a patient for weekly psychotherapy under supervision. You may want to ask me more about this later on but I gave a paper on this student psychotherapy scheme in the early '60s. It was then that Professor Sir Denis Hill, who at that time was the first Professor of Psychiatry at the Middlesex Hospital, heard me talk and invited me to join his Department at the Middlesex Hospital as his senior lecturer in psychotherapy. By then my interest in psychosomatic medicine, analytical psychotherapy and in the teaching of psychiatry was becoming more widely known. This, to my great surprise, led to my receiving a handwritten letter from Sir Aubrey Lewis, saying that the psychoanalyst William Hoffer, who was psychotherapist and consultant at the Maudsley Hospital, was due to retire in a year's time; if I were interested in becoming his successor, he would be pleased to discuss this with me. This was particularly surprising to me, as I had no qualifications in psychiatry nor had I had any formal training, except for the three months in the army in India mentioned earlier. When I met Sir Aubrey I had a long very friendly interview with him. At the end of it he said he hoped I would put in for the post when it was advertised in about a year from then. To my amazement, at the appointments committee a year later the few questions on psychotherapy Sir Aubrey asked me were almost identical to those he had asked when we had first met. This is how I became a consultant in the Psychotherapy Unit at the Maudsley. There one of my main interests became the teaching of psychotherapy to psychiatric trainees. In building up the Psychotherapy Unit I was greatly helped by my colleague, the psychoanalyst Henri Rey. We soon became friends and worked together in the Unit for many years until he retired.
SB It is noteworthy that as one of the most distinguished psychotherapy practitioners in the country you did not actually have a formal training. If I may say, you almost seem quite proud of this and I gather it was a point in your discussion with Sir Aubrey when you went to see him.

HW Yes, that is true. I felt it was only right, during my talk with Sir Aubrey, to mention first that I had had no formal training in psychiatry. To that he replied, "You can't expect to have done everything." He also said he had noticed I was not a member of the British Psychoanalytical Society. I told him that my training in analytical psychotherapy was based on my own analysis, supervision and clinical experience, although I sometimes regretted not having had formal training in psychoanalysis but valued my independence. He seemed to be satisfied with this reply.

SB This is most relevant to my own interest because I myself see psychotherapy as requiring an eclectic or integrationist viewpoint. In other words, that we don't get stuck with models from which we cannot deviate and become constrained thereby. It seems to me that you have come to represent that integrationist position.

HW I agree with you only in as far as one must not become constrained by a rigid theoretical model; if one were there would be no room for originality and new discoveries. However, I think one can practise psychotherapy only if one has a theoretical model in one's mind which one can rely upon but which is open to change. In fact, what has always impressed me most about Freud was his ability to alter his theoretical model in the light of new observations. The psychoanalytical model has helped me most in my work as a psychotherapist because its concepts, especially those concerned with the influence of childhood experience, inner conflicts, unconscious processes and re-living the past in the transference, all provide meaningful experiences for our patients and help them to change and recover. But I want to add something to that. Of course, the British Psychoanalytical Society has had its own struggles and divisions of opinion, especially between the contemporary Freudian and the Kleinian groups, and the independent group in between. However, although different views remain, the Society has become much more integrated and, incidentally, there is now much more common ground between Freudian and Jungian analysts than there used to be. 
SB You say integrated, but yet there were these separate forces which often collided with each other, perhaps the independents less so. So where did you stand and where do you stand in this? Are you the sort of psychoanalytically oriented therapist who is willing to take a variety of ideas from within the analytic tradition and integrate them that way? I suppose that is what I had in mind when I was referring to the integrationist's position and how I thought you yourself functioned.

HW Yes, I consider myself to be a psychoanalytic psychotherapist and have always tried to integrate different psychoanalytic concepts and approaches in my work with patients, as appropriate. This has helped me to remain open to new developments and new ideas and to use these in my clinical work and as a teacher. This openness may also have influenced some of my students at $\mathrm{UCH}$ and at the Maudsley so that several of them ultimately became psychoanalysts. Although I have not gone through formal psychoanalytic training myself, I felt extremely honoured when some five years ago or so the British Psychoanalytical Society offered me honorary membership. This now makes it possible for me to mix with many old friends in the Society and I enjoy and benefit from that a great deal.

SB I wonder if, as part of this openness that you refer to, you became interested in group analysis? I know that you were actively involved in the Institute of Group Analysis and indeed were its chairman for many years.

HW My interest in group analysis developed while I was working as consultant psychotherapist at UCH and at the Maudsley where Michael Foulkes had introduced the practice of group analysis. Both Henri Rey and I found that many of our patients benefited from group therapy. Also we had a long waiting list of patients and soon realised that time could be saved if some of them were treated in groups.

SB I actually well remember running groups at the Maudsley when I was a senior registrar there in the early '70s. I always did wonder then, and perhaps still do now, how you established a bridge between working intensely with individuals and in the same day working with groups.

HW Well, I think there are many links between individual psychoanalytic psychotherapy on the one hand and group analysis on the other. Michael Foulkes, the originator of group analysis, was a psychoanalyst before he developed group analysis. I think that when, say, eight patients are treated together in a group each of them brings his own inner world and past and present experience into the group. Therefore, in order to understand what happens in a group one must understand individual psychodynamics and psychopathology. In the Institute of Group Analysis which is concerned with the training of group analysts I have always felt it to be important for the trainees to start their training by getting a proper grounding in psychoanalytic concepts and how these apply to groups. So, it wasn't difficult for me at the Maudsley and at $\mathbf{U C H}$, where by then I was spending the other half of my time, to do both individual psychotherapy and run groups.

In fact, when I run groups I think not only of the group as a whole but also of each of its members and how they interact; after all, it is the individual patient who, we hope, will benefit from the process. Moreover, some patients need individual therapy first and later benefit from joining a group. Michael Foulkes and I had quite a number of discussions on these issues. How a group can bring about change in the individual was brought home to me by an experience I have never forgotten. A patient in the open group you observed was extremely schizoid and very frightened when he first joined it. He always came early, took one chair out of the circle and sat in a corner, hiding behind a newspaper throughout the group for the first year or so. From time to time individual group members, and occasionally I, would make a comment to see whether he was listening; gradually he began to respond to this by lowering the paper and looking at the rest of us before once more hiding behind his paper. Slowly he became an active and ultimately the oldest member of the group. He stayed in that group for ten years and the ending was most moving. He had by now become well established professionally and in his personal life, having previously been a total isolate and a failure. During his last group all the members and I were very sad at his leaving and his final comment was: "It is very hard, but I know it is time for me to go; after all, this is the only family I have ever had".

Part II of this interview will be published in the July issue of the Psychiatric Bulletin. 